\title{
APLIKASI PENGGUNAAN JOYSTICK SEBAGAI PENGENDALIAN REMOTE CONTROL WEAPON STATION (RCWS) SENJATA MESIN RINGAN (SMR)
}

\author{
Arif Eko Pambudi, Luqman Maajid, Jainur Rohman, Irfan Mujahidin \\ Jurusan Teknik Elektro UNMER Malang \\ Departemen Elektronika Sistem Senjata LEMJIANTEK Malang \\ e-mail: arifekop@gmail.com
}

\begin{abstract}
Abstrak
Remote Control Weapon Station (RCWS) Senjata Mesin Ringan (SMR) dibuat untuk mendukung tugas pokok TNI AD dalam rangka melaksanakan tugas operasi tempur, sehingga diperoleh daya guna tempur yang lebih efektif, efisien, profesional dan modern dalam mendukung terciptanya kemandirian teknologi Alutsista TNI AD. Perencanaan dan pembuatan alat dibangun dengan menggunakan perangkat keras dan perangkat lunak. Perangkat keras yang digunakan yaitu Joystick, Motor DC, mikrokontroler ATmega32, Driver L298, IRF3205 dan mekanik. Sedangkan perangkat lunak yang digunakan yaitu Basic Compiler (BASCOM) sebagai alat pengendali. Dalam pembuatan alat yang dimaksud agar dapat berfungsi dengan baik, maka diperlukan pemahaman yang mendalam tentang karakteristik dan cara kerja komponen-komponen yang digunakan. Hal ini perlu dikuasai sebaik-baiknya untuk menghindari kesalahan penggunaan komponen yang mengakibatkan kegagalan dalam pembuatan alat. Pada perencanaan hardware akan meliputi seluruh perihal yang digunakan pada sistem. Pada perencanaan software merupakan piranti lunak meliputi flowchart dan software secara umum. Perangkat tersebut saling terintegrasi sehingga dalam kerjanya akan maksimum sesuai apa yang diharapkan.
\end{abstract}

Kata Kunci: Remote Control Weapon Station (RCWS), Senjata Mesin Ringan (SMR), Joystick

\section{Pendahuluan}

Dalam meningkatkan profesionalisme prajurit di beberapa negara maju telah menerapkan sistem Remote Control Weapon Station (RCWS) yang menggunakan Joystick untuk kendali manual guna mendukung tugas pokok satuan tempurnya. Dengan melihat kondisi saat sekarang dimana perkembangan teknologi yang begitu pesat dengan alat peralatan dan perlengkapan tempur yang menggunakan sistem teknologi yang canggih[1][2]. Untuk itu dalam pembuatan alat tersebut akan membantu personel untuk menggerakkan senjata Minimi pada RCWS baik secara elevasi dan azimut serta gerak solenoid dengan menggunakan joystick secara manual. Dimana dalam pelaksanaannya dapat membantu tugas pokok dari satuansatuan tempur dan mengurangi jatuhnya korban dalam melaksanakan tugas tersebut[3][4].

\section{Metode penelitian}

Dalam perancangan dan pembuatan alat terdapat beberapa variabel yang akan diuji dan diukur untuk pengambilan data serta mengetahui sistem kerja dari alat yang dibuat. Variabel tersebut meliputi:

Variabel terikat dalam perancangan meliputi:

1. Mikrokontroler AVR ATmega32 (Port input dan output).

2. Driver H-Bridge untuk posisi azimut dan elevasi RCWS.

3. Driver solenoid (picu tembak).

Variabel bebas dalam perancangan alat meliputi:

1. Arah gerak joystick kendali azimut dan elevasi RCWS.

2. Kecepatan pergerakkan joystick.

Blok input merupakan bagian dari sistem alat yang memberikan input atau masukan berupa tegangan kepada mikrokontroler. Blok process adalah bagian dari sistem alat (mikrokontroler) yang bertugas memproses dan mengeksekusi perintah program yang sesuai input yang diterima. Blok output merupakan bagian dari sistem yang bertugas menjalankan sistem sesuai fungsi peralatan tersebut dirancang, berdasarkan kondisi yang diberikan oleh blok proses[5][6]. Skema pemodelan alat seperti pada Gambar 1 


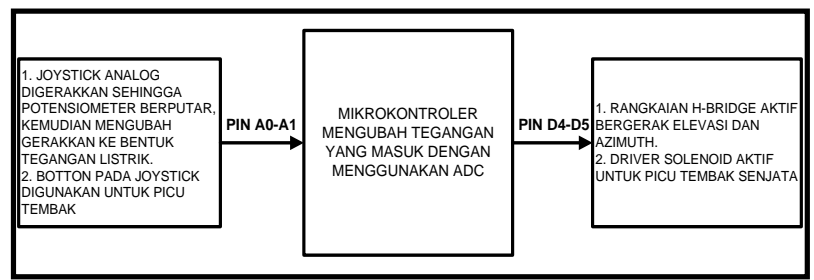

Gambar 1 Skema Pemodelan.

\subsection{Perencanaan Alat}

Perancangan hardware meliputi perancangan dan perakitan rangkaian minimum sistem mikrokontroler ATmega32, perancangan dan perakitan rangkaian $\mathrm{H}$-bridge kendali motor serta solenoid. Sedangkan perancangan software meliputi perancangan list program bahasa program yang akan dimuat pada mikrokontroler untuk mengeksekusi dan menjalankan perintah program saat mikrokontroler menerima masukan[7][8]. Adapun blok diagram alat secara keseluruhan ditunjukkan seperti pada Gambar 2

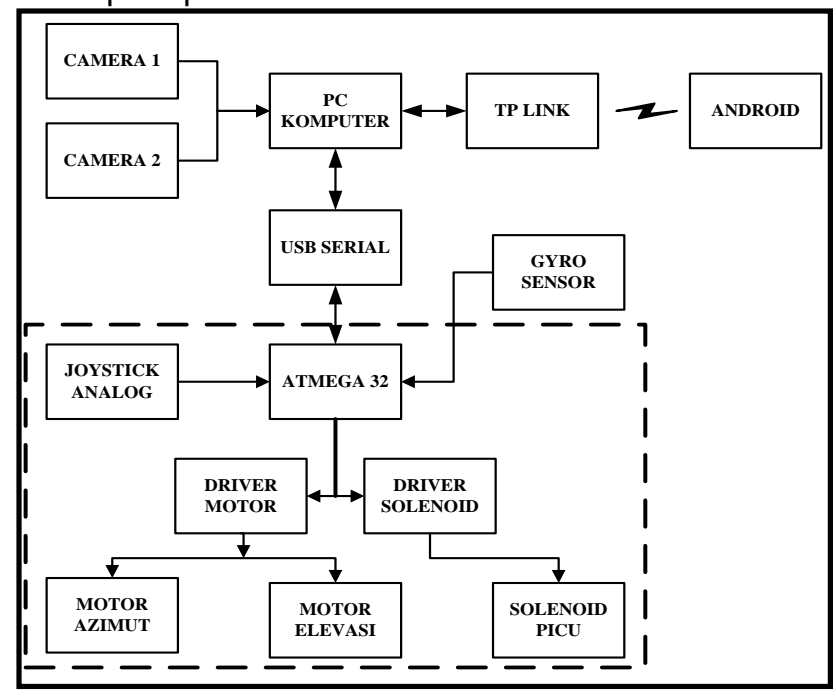

Gambar 2 Blok Diagram Alat Keseluruhan

Gambar 2 adalah blok diagram perencanaan alat keseluruhan. Prinsip kerja dari blok diagram sistem kendali manual adalah data yang diterima dari modul joystick kemudian masuk menuju mikrokontroler ATmega32. Data tersebut kemudian diolah dan dikirim kembali menuju driver motor untuk menggerakkan motor elevasi dan azimuth maupun solenoid guna menarik picu senjata Minimi, tergantung dari data yang dikirim oleh ATmega32[9][10]. Perancangan perangkat keras (hardware) seperti pada Gambar 3

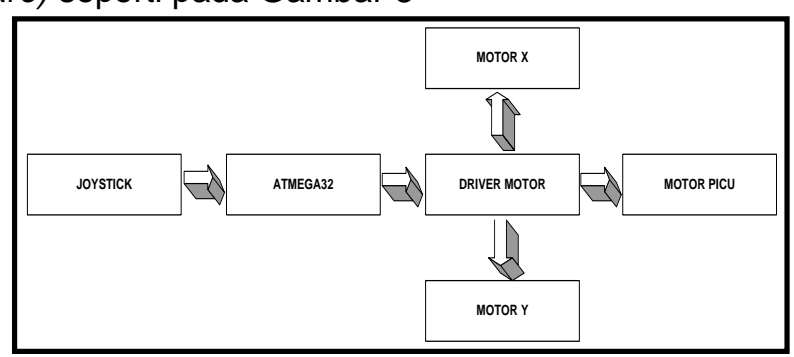

Gambar 3 Blok Diagram Alat

Perencanaan perangkat keras (hardware) meliputi beberapa perancangan rangkaian yang akan diintegrasikan menjadi satu sistem kerja, yaitu:

Dalam perancangan pembuatan RCWS SMR, sistem perencanaan mekanik menggunakan bahan yang sudah tersedia oleh karena itu dibutuhkan suatu gambar untuk merancang RCWS SMR yang akan ditunjukkan dalam Gambar 4[11][12]. 


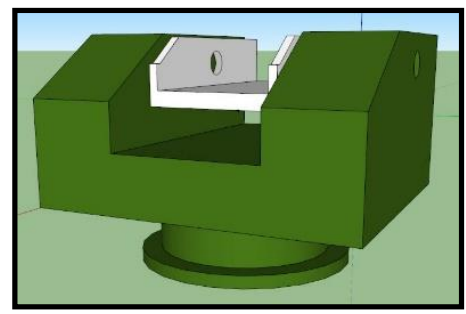

Gambar 4 Desain Mekanik.

Rangkaian minimum sistem adalah rangkaian minimal untuk dapat mengaktifkan chip mikrokontroler sehingga dapat bekerja (running). Rangkaian ATmega32 sesuai dengan perencanaan ditunjukan pada Gambar 5

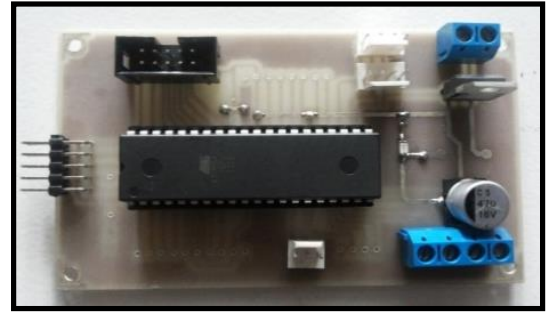

Gambar 5 Rangkaian Minimum Sistem ATmega32

Driver motor merupakan rangkaian yang berfungsi untuk menggerakkan motor serta untuk menghubungkan motor DC dengan catu daya. Secara umum driver motor mempunyai fungsi menguatkan arus dari kontroler dan sebagai saklar untuk menggerakkan motor[13][14]. Skema perancangan seperti pada Gambar 6

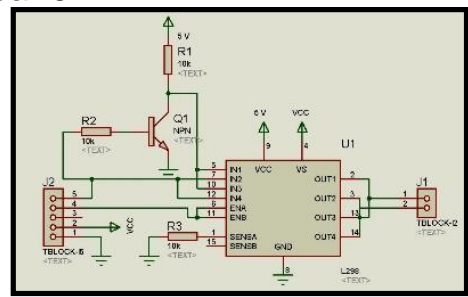

Gambar 6 Skema Rangkaian Driver Motor Azimut dan Elevasi

Rangkaian driver Solenoid yang akan digunakan pada perancangan alat dengan menggunakan transistor MOSFET. Transistor IRF3205 sebagai komponen utama. Skema perancangan rangkaian driver solenoid seperti pada Gambar 7

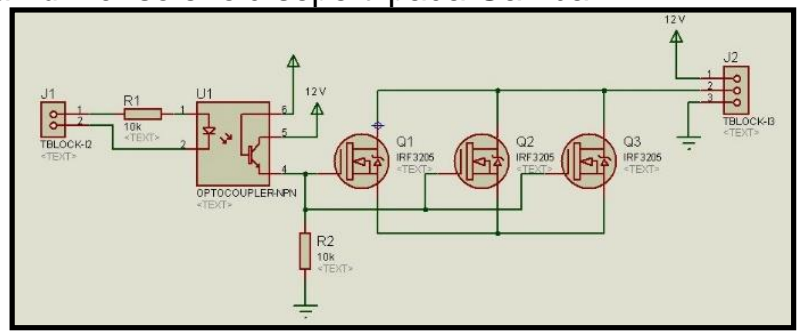

Gambar 7 Skema Rangkaian Driver Solenoid

Gambar 7 adalah rangkaian saklar transistor yang berfungsi sebagai rangkaian saklar elektronik. Driver diberi masukkan VCC sebesar 12 Volt. Kemudian menuju tiga buah transitor IRF3205 yang dirangkai secara paralel[15][16]. Konfigurasi transistor paralel bertujuan untuk menguatkan kapasitas arus transistor. Pada konfigurasi transistor secara paralel ini kaki drain dihubungkan dengan drain, source dengan source dan gate dengan gate. Optocoupler ditambahkan sebagai pengaman transistor dari lonjakan tegangan induksi yang dihasilkan oleh beban induktif dari Solenoid. Sehingga apabila ada arus balik yang terlampau tinggi tidak akan merusak komponen lain[17].

Sistem kerja alat menggunakan variable resistor yang digunakan untuk mendeteksi perubahan resistensi. Bentuk joysick yang akan digunakan seperti pada Gambar 8 


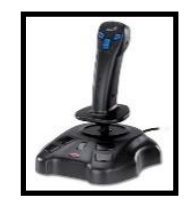

Gambar 8 Fisik Joystick Analog

Kontrol Logika fuzzy digunakan sebagai pengendali agar dicapai arus dan tegangan yang konstan. Diagram blok logika fuzzy ditunjukkan dalam Gambar 9

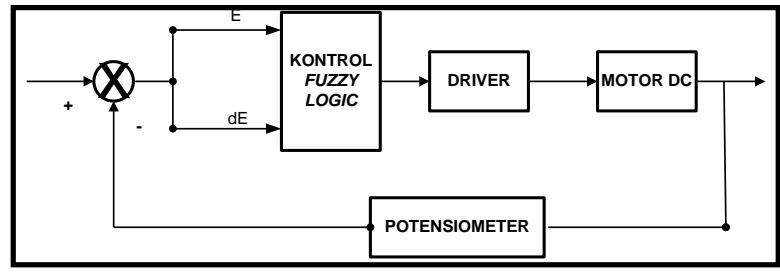

Gambar 9 Diagram Blok Kontrol Logika Fuzzy

Blok diagram kerja mikrokontroler dalam mengeksekusi software yang ditanamkan didalamnya, dapat dilihat pada Gambar 10

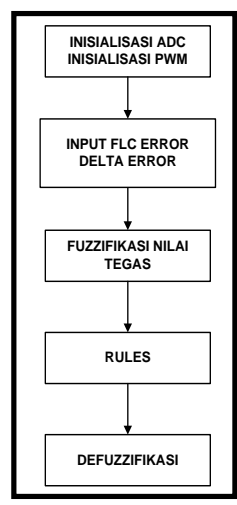

\section{Gambar 10 Blok Diagram Perangkat Lunak}

Proses inisialisasi ADC meliputi proses penentuan clock, tegangan referensi, format output, dan mode pembacaan. Register yang perlu diset nilainya adalah ADMUX (ADC Multiplexer Selection Register), ADCSRA (ADC Control and Status Register A) dan SFIOR (Spesial Function IO Register)[18][19]. Sedangkan inisialisasi PWM (Pulse Width Modulation) meliputi setting mikrokontroler ATmega32 agar dapat mengeluarkan output analog pada pin D berupa sinyal analog.

Menentukan jenis fungsi keanggotaan (membership function) masukkan dari error. Fungsi keanggotaan untuk masukkan error ditunjukkan pada Gambar 11

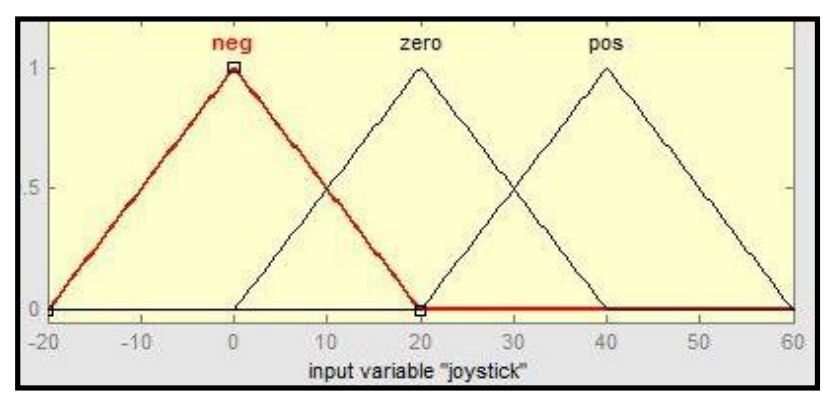

Gambar 11 Fungsi Keanggotaan Masukkan Error

Menentukan jenis fungsi keanggotaan (membership function) masukkan dari delta error. Fungsi keanggotaan untuk masukkan delta error ditunjukkan pada Gambar 12 


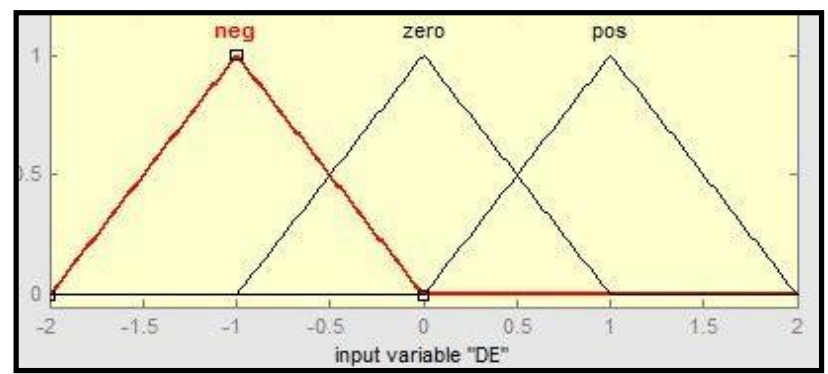

Gambar 12 Fungsi Keanggotaan Masukkan Delta_Error

Fuzzifikasi meliputi proses merubah dari besaran bukan fuzzy (crisp) ke besaran fuzzy sehingga didapat derajat fungsi keanggotaan. Operasi fuzzifikasi melibatkan transformasi sebuah himpunan bukan fuzzy ke dalam himpunan fuzzy[20][21].

Rules didasarkan pada bentuk jika-maka. Setelah crispt input dirubah menjadi input fuzzy, selanjutnya dioleh sesuai dengan kaidah aturnya.

Tabel 1 Tabel Kaidah Atur

\begin{tabular}{|c|c|c|c|}
\hline $\begin{array}{c}\text { Error } \\
\Delta \text { Error }\end{array}$ & Negatif & Zero & Positif \\
\cline { 1 - 3 } Negatif & cepat & sedang & sedang \\
\hline Zero & sedang & lambat & sedang \\
\hline Positif & sedang & sedang & cepat \\
\hline
\end{tabular}

lihat hasil output PWM dengan menggunakan software Matlab seperti ditunjukkan pada Gambar 13

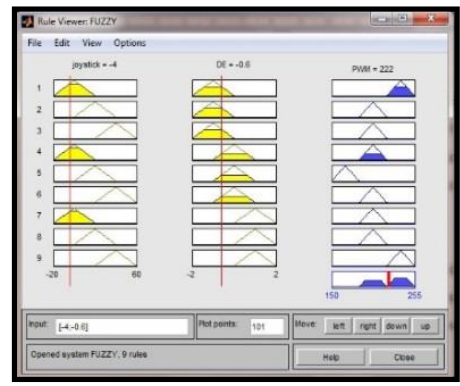

Gambar 13 Membership Functoin Error Rule 1

\section{Hasil dan Analisis}

Hasil pengujian rangkaian mikrokontroler ATmega32 seperti pada Tabel 2 Tabel 2 Pengujian Rangkaian Mikrokontroler

\begin{tabular}{|c|l|c|c|}
\hline NO & \multicolumn{1}{|c|}{ PENGUJIAN } & KONDISI & HASIL ( Volt / Ampere) \\
\hline 1. & Tegangan Sumber & Aktif & $5,01 \mathrm{~V} / 0,5 \mathrm{~A}$ \\
& (Vcc) & & \\
\hline 2 & V Port A.0 (Port in) & Logic 0 & $0,02 \mathrm{~V} / 0,00 \mathrm{~A}$ \\
& & Logic 1 & $4,97 \mathrm{~V} / 0,5 \mathrm{~A}$ \\
\hline 3. & V Port B.5(Port out) & Logic 0 & $0,01 \mathrm{~V} / 0,00 \mathrm{~A}$ \\
& & Logic 1 & $5,02 / 0,25 \mathrm{~A}$ \\
\hline
\end{tabular}

Berdasarkan data yang didapat pada pengujian port mikrokontroler yang digunakan sebagai port input maupun port output, tegangan pada port A0 sebagai port input pada saat logic 0 (low) adalah 0,02 Volt dan pada saat kondisi logic 1 (high) 4,97 Volt. Sedangkan tegangan pada port B5 sebagai port output pada saat kondisi logic 0 (low) adalah 0 Volt dan pada saat kondisi logic 1 (high) 5,02 Volt[22][23]. 
Data yang didapat pada pengujian nilai keluaran PWM baik untuk sudut azimut dan elevasi, diperoleh selisih besar nilai output PWM antara pengujian dan perhitungan manual.

Melalui proses perhitungan didapatkan dengan menggunakan rumus persamaan garis lurus sebagai berikut[24][25]:

$\frac{X-X 1}{X 2-X 1}=\frac{Y-Y 1}{Y 2-Y 1}$

Sehingga untuk menghitung besar PWM gerakkan joystick belakang dan kanan dengan nilai X1 $=585, \mathrm{X} 2=885, \mathrm{Y} 1=150$ dan $\mathrm{Y} 2=255$ didapatkan persamaan sebagai berikut:

$\frac{X-X 1}{X 2-X 1}=\frac{Y-Y 1}{Y 2-Y 1}$

$\frac{X-585}{885-585}=\frac{Y-150}{255-150}$

$\frac{X-585}{300}=\frac{Y-150}{105}$

$105 X-61425=300 Y-45000$

$105 X-61425+45000=300 Y$

$105 X-16425=300 Y$

Dimana:

$\mathrm{X} 1$ = Batas atas ADC joystick dalam kondisi normal

$\mathrm{X} 2$ = ADC maksimal yang dihasilkan joystick

$\mathrm{Y} 1=\mathrm{PWM}$ minimal motor dapat berputar

Y2 = PWM maksimal putaran motor

Maka apabila nilai ADC joystick $=884$ didapatkan nilai PWM sebagai berikut:

$105 X-16425=300 Y$

$105.884-16425=300 Y$

$92820-16425=300 Y$

$76395=300 Y$

$Y=\frac{76395}{300}$

$Y=254,65$ dibulatkan menjadi 255

Dan seterusnya sesuai dengan ADC yang diperoleh dari pergerakkan joystick. Sedangkan untuk menghitung besar PWM gerakkan joystick depan dan kiri dengan nilai $\mathrm{X} 1=540, \mathrm{X} 2=$ $165, Y 1=150$ dan $Y 2=255$ didapatkan persamaan sebagai berikut[26][27]:

$\frac{X-X 1}{X 2-X 1}=\frac{Y-Y 1}{Y 2-Y 1}$

$\frac{X 2-X 1}{X-540}=\frac{Y-Y 1}{Y}-150$

$\overline{165-540}=\overline{255-150}$

$\frac{X-540}{-375}=\frac{Y-150}{105}$

$105 X-56700=-375 Y+56250$

$105 X-56700-56250=-375 Y$

$105 X-112950=-375 Y$

Dimana:

$\mathrm{X} 1$ = Batas bawah ADC joystick dalam kondisi normal

$\mathrm{X} 2$ = ADC minimal yang dihasilkan joystick

$\mathrm{Y} 1=\mathrm{PWM}$ minimal motor dapat berputar

Y2 = PWM maksimal putaran motor

Maka apabila nilai ADC joystick $=159$ didapatkan nilai PWM sebagai berikut:

$105 X-112950=-375 Y$

$105.159-112950=-375 Y$

$16695-112950=-375 Y$

$-96255=-375 Y$

$Y=\frac{-96255}{-375}$ 
$Y=256,68$ dibulatkan menjadi 257

Berdasarkan Tabel 4.7 dapat disimpulkan, dengan perhitungan untuk penyimpangan rata-rata berdasarkan nilai PWM yang ditampilan pada hyperterminal sebagai berikut[28][29]:

Kesalahan rata - rata $=\frac{\sum \text { Selisih }}{\mathrm{n} \text { pengujian }}$

Kesalahan rata - rata $=\frac{354}{15}$

Kesalahan rata - rata $=23,6 \%$

Berdasarkan Tabel 4.8 dapat disimpulkan, dengan perhitungan untuk penyimpangan rata-rata berdasarkan nilai PWM yang ditampilan pada hyperterminal sebagai berikut[30][31]:

Kesalahan rata - rata $=\frac{\sum \text { Selisih }}{\mathrm{n} \text { pengujian }}$

Kesalahan rata - rata $=\frac{49}{15}$

Kesalahan rata - rata $=3,26 \%$

4. Simpulan

Berdasarkan hasil perencanaan, pembuatan dan pengujian aplikasi, maka diambil kesimpulan sebagai berikut :

1. Joystick dapat digunakan untuk menggerakkan RCWS arah azimut dan elevasi. Untuk menggerakkan elevasi joystick menghasilkan nilai ADC minimal 161 dengan tegangan 0,79 volt dan nilai $A D C$ maksimal 4,33 volt dengan nilai $A D C 887$ dengan kesalahan pengujian dan perhitungan sebesar $1,86 \%$. Sedangkan untuk menggerakkan azimut joystick menghasilkan nilai ADC minimal 196 dengan tegangan 0,95 volt dan nilai ADC maksimal 899 dengan nilai tegangan 4,39 volt dengan kesalahan pengujian dan perhitungan sebesar $3,13 \%$.

2. Motor digerakkan dengan metode fuzzy logic sehingga menghasilkan nilai PWM. PWM minimum untuk menggerakkan joystick yaitu 150 dan batas maksimumnya 255. Pada pergerakkan azimut nilai PWM pengujian dan perhitungan mengasilkan error yang cukup besar yaitu $23,6 \%$. Ini dikarenakan adanya pembatasan gerakkan oleh limit switch, sehingga putaran motor tidak mencapai kecepatan maksimal. Selain itu senjata minimi yang dipasang pada RCWS direncanakan untuk menembak sasaran -20 derajat sampai 50 derajat. Tetapi untuk pergerakkan azimut motor dapat mencapai kecepatan maksimal dengan error pengujian dan perhitungan sebesar 3,26\% karena motor berputar 360 derajat.

3. Solenoid yang digunakan dalam perancangan dapat bekerja dengan baik dengan tegangan rata-rata 5,063 volt.

\section{References}

[1] M. A. R. Arif Rahman Hakim, Sumardi, "Kontrol Posisi Pada Sistem Pergerakan Mobile Robot Kinematic," Article, 2015.

[2] X. Zhang, X. Li, and K. Lu, "Research on an intelligent solar tracking system based on LPC2131," in Proceedings - 2012 3rd IEEE International Conference on Network Infrastructure and Digital Content, IC-NIDC 2012, 2012.

[3] M. Octavian, Ari; Darmawan, Hofman; Nurohmah, Hidayatul; Ali, "Optimasi Dual Axis Tracking Untuk Photovoltaic Berbasis Firefly Algorithm dan Ant Colony Optimization," SinarFe7, 2018.

[4] I. Mujahidin and P. S. Arinda, "Antena Compact Double Square Marge 2, 6GHz Dengan Output Perbedaan Fase 90 Derajat Untuk Aplikasi LTE," JEECAE (Journal Electr. Electron. Control. Automot. Eng., vol. 4, no. 2, pp. 273-278, 2019.

[5] Handy Wicaksono and Josaphat Pramudijanto, "Kontrol PID Untuk Pengaturan Kecepatan Motor DC Dengan Metode Tuning Direct Synthesis," J. Tek. Elektro, 2004.

[6] T. A. S, A. Rabi', D. Minggu, and I. Mujahidin, "Frequency Hopping Video Real Time Untuk Pengamanan Data Pengintaian Operasi Inteligence TNI," JASIEK (Jurnal Apl. Sains, Informasi, Elektron. dan Komputer), 2019.

[7] F. Greg Shinskey, "PID control," in Measurement, Instrumentation, and Sensors Handbook: Spatial, Mechanical, Thermal, and Radiation Measurement, Second Edition, 2017. 
[8] J. A. Stankovic, "Research directions for the internet of things," IEEE Internet Things J., 2014.

[9] D. Hermanto, "Sistem Pengontrol Lampu Menggunakan Fitur Pengenalan Suara Manusia," J. Infomedia, 2018.

[10] I. Mujahidin, R. Yuwono, and A. Mustofa, "Rancang Bangun Rectifier Antenna Mikrostrip Ufo Pada Frekuensi Ultra Wideband (UWB) Sebagai Pemanen Energi Elektromagnetik," J. Mhs. TEUB, vol. 3, no. 2, 2015.

[11] A. Dorri, S. S. Kanhere, R. Jurdak, and P. Gauravaram, "Blockchain for loT security and privacy: The case study of a smart home," in 2017 IEEE International Conference on Pervasive Computing and Communications Workshops, PerCom Workshops 2017, 2017.

[12] J. Lasmono, A. P. Sari, E. Kuncoro, and I. Mujahidin, "Optimasi Kerja Peluncur Roket Pada Robot Roda Rantai Untuk Menentukan Ketepatan Sudut Tembak," JASIEK (Jurnal Apl. Sains, Informasi, Elektron. dan Komputer), 2019.

[13] R. L. Singgeta and Sompie, "Rancang Bangun Robot Boat Navigasi Tanpa Awak," EJournal Tek. Elektro Dan Komput., 2013.

[14] M. Ali, I. Umami, and H. Sopian, "Particle Swarm Optimization (PSO) Sebagai Tuning PID Kontroler Untuk Kecepatan Motor DC," Intake J. Penelit. IImu Tek. Dan Terap., 2016.

[15] S. Monk, Raspberry Pi Cookbook. 2015.

[16] B. F. Hidayatulail and I. Mujahidin, "Potential Of 77, $78 \mathrm{~mW}$ Red Diode Laser For Photodynamic," JEEMECS (Journal Electr. Eng. Mechatron. Comput. Sci., vol. 2, no. 2, 2019.

[17] R. K. Srivastava and W. Jozewicz, "Flue gas desulfurization: The state of the art," J. Air Waste Manag. Assoc., 2001.

[18] Z. Akhondali, M. Dianat, and M. Radan, "Electronic Physician ( ISSN : 2008-5842 )," Electron. Physician, 2015.

[19] S. K. Sugiarto, I. Mujahidin, and A. B. Setiawan, "2, $5 \mathrm{GHz}$ Antena Mikrostrip Polarisasi Circular Model Patch Yin Yang untuk Wireless Sensor," JEECAE (Journal Electr. Electron. Control. Automot. Eng., vol. 4, no. 2, pp. 297-300, 2019.

[20] R. M. Murray, Z. Li, and S. Shankar Sastry, A mathematical introduction to robotic manipulation. 2017.

[21] R. Yuwono, I. Mujahidin, A. Mustofa, and Aisah, "Rectifier using UFO microstrip antenna as electromagnetic energy harvester," Adv. Sci. Lett., 2015.

[22] S. Sicari, A. Rizzardi, L. A. Grieco, and A. Coen-Porisini, "Security, privacy and trust in Internet of things: The road ahead," Computer Networks. 2015.

[23] M. T. Prakarsa, D. Wahyuni, N. Rachman, and I. Mujahidin, "Optimasi Sistem Komunikasi Dari Ht Dengan Hp Dalam Pelaksanaan Tugas Operasi Tni Ad Menggunakan Metode DTMF," JASIEK (Jurnal Apl. Sains, Informasi, Elektron. dan Komputer), 2019.

[24] Asnil and I. Husnaini, "Sistem Kontrol Optimal Pada Kontrol Posisi Motor Dc," Tek. Energi, 2010.

[25] I. Mujahidin, "Directional $1900 \mathrm{MHz}$ Square Patch Ring Slot Microstrip Antenna For WCDMA," JEEMECS (Journal Electr. Eng. Mechatron. Comput. Sci., 2019.

[26] M. Daisy A.N Janis, David Pang, ST., MT, J. O. Wuwung ST., "Rancang Bangun Robot Pengantar Makanan Line follower," Tek. Elektro dan Komput., 2014.

[27] I. Mujahidin, S. H. Pramono, and A. Muslim, "5.5 GHz Directional Antenna with 90 Degree Phase Difference Output," 2018.

[28] H. Fitriawan, O. Pucu, and Y. Baptista, "Identifikasi Plat Nomor Kendaraan Secara Off-Line Berbasis Pengolahan Citra Dan Jaringan Syaraf Tiruan," Electr. J. Rekayasa dan Teknol. Elektro, 2012.

[29] R. Jamil, L. Ming, I. Jamil, and R. Jamil, "Application and Development Trend of Flue Gas Desulfurization (FGD) Process: A Review," Int. J. Innov. Appl. Stud. ISSN, 2013.

[30] Y. Yu, P. G. M. Baltus, A. De Graauw, E. Van Der Heijden, C. S. Vaucher, and A. H. M. Van Roermund, "A $60 \mathrm{GHz}$ phase shifter integrated with LNA and PA in $65 \mathrm{~nm}$ CMOS for phased array systems," in IEEE Journal of Solid-State Circuits, 2010.

[31] I. Appelbaum, B. Huang, and D. J. Monsma, "Electronic measurement and control of spin transport in silicon," Nature, 2007. 